\title{
Breeding for nutritive quality
}

\section{By J. P. Cooper and E. L. BREese, Welsh Plant Breeding Station, Aberystwyth}

Whilst herbage grasses and legumes are grown primarily to provide digestible energy and other nutrients for farm livestock, plant breeders have tended to concentrate on total or seasonal yield of $D M$, i.e. on the maximum fixation of energy by the crop, with any assessment of its nutritive value being left to a later stage of evaluation. In terms of providing the maximum amount of utilizable energy, together with the necessary levels of other nutrients, however, consideration should be given to the possibility of improving nutritive quality directly by breeding. The present paper outlines some of the problems involved in this approach and assesses the possibilities of breeding for nutritive quality.

The first step is to identify those features of the crop which determine its nutritive quality. The provision of digestible energy is of primary importance; but protein or mineral content can also limit animal production, and in some herbage species the presence of harmful compounds, such as oestrogens, can pose problems. Information on the relative importance of these features may be obtained both from our knowledge of the nutritional requirements of the ruminant and from feeding or grazing trials, followed by attempts to identify the physical or chemical basis of differences in animal performance.

Following the identification of the most important nutritional components, the nutritionist and the breeder need to cooperate to develop rapid and reliable screening tests which can deal with the large number of small samples involved in a breeding programme. These screening techniques can then be used to develop material with the required nutritional characteristics, either by selection from within existing adapted varieties, or by introduction from wild ecotypes or even from other closely related species. Finally, the resulting selection lines or potential varieties must be critically assessed in terms of animal performance, under grazing or in indoor feeding trials or both (Cooper, 1973; Jones et al. 1974).

\section{Components of nutritive quality}

In considering the application of the above approach some of the most important components of nutritive value are those concerned with efficient conversion of energy by the ruminant; these include digestibility and those features which determine voluntary intake and metabolic utilization of the feed. Animal production may also be limited by a shortage of other necessary constituents, such as protein and minerals, or by the presence of deleterious compounds such as oestrogens, or bloat producing factors. In addition to these characteristics which directly affect nutritive value, it is important to consider those physical or chemical $0029-6651 / 80 / 3933-4304$ Sor .00 (C) 1980 The Nutrition Society 
features which influence efficiency of conservation, either as hay or silage, and looking ahead, those required for other forms of processing, such as microbial digestion or direct extraction of leaf protein.

Energy conversion. Digestibility, which determines the proportion of the feed which can actually be utilized by the animal, was one of the earliest nutritional features to be considered by the plant breeder. The assessment of digestibility by standard feeding trials is, however, clearly not suitable for the screening of large numbers of small samples in a breeding programme, and various chemical assays, such as normal acid fibre or acid detergent fibre have been employed for this purpose. An important step was the development of in vitro techniques using rumen liquor, often with pre-digestion with pepsin. The results of this technique are highly correlated with those of standard feeding trials, but it has the disadvantage of requiring fistulated sheep or cattle, while lack of reproducibility between runs may be a problem (Raymond, I 969; Barnes, 1973). The more recent development of the two-stage pepsin-cellulase technique obviates the need for maintaining fistulated animals and gives improved repeatability throughout the year (Jones \& Hayward, 1975; Jones, 1975).

It has long been recognized that digestibility declines with increasing maturity of the crop, i.e. with increasing steminess, and the breeder had already improved digestibility by selecting for a greater proportion of leaf to stem, while the provision of varieties with a range of flowering dates allows for flexibility in utilization (Raymond, 1969). Even at the same stage of maturity, however, species and varieties may differ in digestibility-cocksfoot, for instance, being usually some to units lower than ryegrass - and appreciable genetic variation has been reported between varieties and individual genotypes of several herbage species, including cocksfoot, ryegrass, bromegrass and lucerne (Cooper, 1973). The effective use of this variation in a breeding programme may pose problems. In cocksfoot, for instance, selection for improved digestibility, as measured on individual spaced plants, was highly successful in producing plants well within the ryegrass range (Cooper, 1973). This improvement was, however, based on larger and more succulent leaves and tillers, and disappeared when the plants were grown under the competitive conditions of a sward. Attempts are now being made to introduce a higher digestibility of the individual leaf from the related Portuguese species Dactylis marina. In the tropical grasses, coastal Bermuda grass and pearl millet, however, breeding for increased digestibility has been shown to result in greater live-weight gains (Burton et al. 1967; Burton et al. 1969).

The importance of voluntary intake in determining animal performance is now well recognized, but the features of the herbage which influence such intake are still far from clear, though digestibility is clearly important since more digestible forages pass more rapidly through the rumen. Legumes usually show a greater intake than grasses, while intake can vary appreciably between individual species and varieties of grasses, even at the same digestibility (Walters, 1971, 1974). Evidence is accumulating on the importance of physical characteristics of the forage which determine its rate of breakdown in the rumen and during 
mastication. Clover feeds, for instance, break down more readily into particles of regular size which pass out of the rumen more quickly than do the longer, more irregularly-shaped fragments derived from grass feeds which have more vascular tissue and a tougher epidermis and cuticle (Ulyatt, 1973; Moseley \& Jones, 1979). Physical measurements, such as leaf tensile strength, shearing strength or fibrosity index which may be associated with more rapid breakdown are being assessed as possible selection criteria in the grasses (Jones, 1975), while the enzymic breakdown of different types of tissue in leaf sections shows promise as a possible screening technique (Selim et al. 1975). Leaf tensile strength for instance, is highly heritable (Wilson, 1965), and high and low selection lines of ryegrass and tall fescue are now being multiplied in preparation for animal feeding trials.

Much of our information on voluntary intake is derived from indoor feeding trials, but other features may be important under grazing. In a recent grazing trial of two perennial ryegrass varieties, one variety, Mascot, gave $12 \%$ increase in live-weight gain, over two years, associated with increased voluntary intake in spite of $4 \%$ lower DM production than S.23 (Evans et al. 1979). No such differences in intake were obtained in indoor feeding trials, suggesting that some aspect of presentation of the herbage to the animal in the field is concerned. Again, indoor feeding trials, using dried herbage, have shown greatly reduced intakes and live-weight gains on timothy, compared with cocksfoot, ryegrass and tall fescue, though this poor performance can be remedied by supplementation with clover (Miles et al. 1969) or with minerals (Patil \& Jones, 1970). In grazing trials on the other hand, timothy swards have provided superior live-weight gains in lambs compared with the above three grasses (Davies \& Morgan, 1979).

Rather less is known about differences in the efficiency of utilization of the energy and other nutrients in the feed actually taken in by the animal, apart from the obvious effect of digestibility. Clovers, for instance, usually provide higher liveweight gains than grasses for the same amount of herbage consumed, possibly as a result of more rapid breakdown and passage of material from the rumen, with consequently more efficient digestion, particularly of protein, in the small intestine. Similarly, within the grasses, the greater live-weight gains obtained from the short-rotation Manawa ryegrass than from perennial ryegrass are associated with more rapid passage of organic matter of Manawa through the rumen (Ulyatt, 1973). Selection for features determining more rapid breakdown of vascular tissue and epidermis may, therefore, result in more efficient utilization as well as greater intake.

Protein and minerals. Even with adequate energy supply, production can be limited by the supply of other nutrients, in particular, protein and minerals. The protein content required will depend on whether the forage is to be used as a complete diet, mainly as an energy source, or as in many legumes, as a high protein supplement. Although in tropical and sub-tropical environments, protein may often be limiting, in intensive grassland systems in temperate environments, the level of protein is not likely to limit annual production. Consequently, although variation in protein content, for the same nitrogen input, has been reported in several grasses, 
including ryegrass, cocksfoot and Phalaris (Cooper, 1973), breeding for higher protein content in temperate species is of doubtful priority.

Mineral content can pose greater problems, particularly in grasses, where the level of certain elements, such as calcium, magnesium and iodine may fall below that required by a high-yielding dairy cow, resulting in specific deficiency conditions such as hypomagnesaemia (Butler \& Jones, 1973). Although the mineral content of herbage will often reflect that of the soil on which it is growing, this relationship can be greatly modified by differences in uptake of particular elements by different species and varieties (Fleming, 1973). Legumes usually have a higher content of many minerals than grasses, including $\mathrm{Ca}$ and $\mathrm{Mg}$, whilst among the grasses, timothy is consistently very low in $\mathrm{Na}$ and also lower in cobalt and $\mathrm{Cu}$ compared with ryegrass and cocksfoot. Even within the ryegrasses, however, large differences have been reported between varieties and individual clones for a wide range of mineral elements, with encouragingly high heritabilities (Cooper, 1973) and selection for increased $\mathrm{Mg}$ has already been incorporated in the Italian ryegrass breeding programme at Aberystwyth. Even so, although it appears possible to breed for more effective uptake of particular mineral elements, the justification for such an approach must take into account the relative cost and practicability of other ways of remedying mineral deficiencies, such as fertilizer application to the sward, direct supplementation to the feed, or the introduction of a legume into the diet.

Harmful constituents. Certain forage species, particularly legumes and brassicas, contain deleterious compounds which can affect animal health, and breeding for absence or low level of these compounds is usually the only satisfactory way to obviate their effects. A major prerequisite of such a breeding programme is identification of the compound or compounds concerned and the development of rapid screening tests for their estimation. One of the most notable examples of such an approach has been the development of non-oestrogenic varieties of subterranean clover in Australia. Many of the original varieties of subterranean clover when fed in quantity were found to cause reproductive disorders in sheep, and this effect was traced to their content of isoflavones, particularly formononetin. Further study revealed considerable variation in isoflavone content between varieties of subterranean clover, while in addition, a number of single gene mutants have been induced which interrupt the normal synthesis of these compounds and which have been successfully incorporated into new varieties (Francis \& Millington, 1965).

Red clover also contains formononetin and impairment of reproductive performance of ewes fed on red clover has been reported from the UK. The development of rapid screening techniques has revealed appreciable genetic variation in formononetin content between and within varieties, for instance, a tenfold range between individual plants of Sabtoron (Gosden, 1978) and high and low formononetin selection lines are now being multiplied for animal feeding trials.

Grasses on the other hand, appear to be relatively free of toxic constituents in the UK, but other examples of deleterious compounds in forages include 
antithyroid compounds such as glucosinolates or the kale anaemia factor (Smethyl-L cysteine sulphoxide) in forage brassicas. Here again the development of rapid screening techniques has revealed useful genetic variation which can be selected in a breeding programme (Gosden, 1978 ).

In the above examples, progress by plant breeding has been possible following identification of the causal compound. In the case of bloat, however, which can be an important problem in many legumes, the development of a suitable screening technique awaits firm information on the causal agent, although certain soluble protein fractions have been implicated, and tannins seem to have a protective effect, possibly by forming a non-foaming complex with the protein (Clarke \& Reid, 1974).

\section{Conclusions}

It is clearly possible to identify at least some of the physical and chemical features of herbage plants which determine their nutritive quality, and to develop rapid and reliable screening techniques which can be used in a breeding programme. Furthermore, appreciable genetic variation exists for many of these nutritive characteristics, which can be selected and combined by the usual breeding procedures.

Before establishing an operational breeding programme for any nutritional characteristic, however, its relative importance in limiting animal production in different farming systems must be considered. Where production is limited by the presence of one or more harmful constituents, such as oestrogens in subterranean clover, a breeding programme is clearly justifiable. For deficiencies in protein and minerals, however, amelioration in other ways, by direct supplementation or by increased use of legumes may be more practical. In an intensive grassland system for instance, the herbage is primarily required to provide the maximum digestible energy, and direct supplementation is clearly possible, but for more extensive systems, as in the hills and uplands, the provision of a complete and balanced diet from the herbage is an important objective.

In all grassland systems, however, an important objective is the provision of more digestible energy per unit of land (or per unit of support energy). The plant breeder needs to produce varieties not only with high digestibility, but also with high intake characteristics and high feed utilization for both grazing and conservation, and for this purpose more comparative information on the relation between forage characteristics and the digestive processes of the ruminant is urgently needed.

Finally, the approach to breeding for nutritive value outlined in this paper has been discussed largely with reference to the use of grasses and legumes as ruminant feed. Possible future utilization for other purposes, by microbial digestion or fractionation for leaf protein, will naturally present its own particular requirements for the plant breeder. 


\section{REFERENCES}

Barnes, R. F. (1973). In Chemistry and Biochemistry of Herbage. Vol. 3, p. 179. [G. W. Butler and R. W. Bailey, editors]. London: Academic Press.

Burton, G. W., Hart, R. H. \& Lowrey, R. S. (1967). Crop Sci. 7, 329.

Burton, G. W., Mouson, W. G., Johnson, J. C., Lowrey, R. S., Chapman, H. D. \& Marchant, W. H. (1969). Agron. F. 52, 173 .

Butler, G. W. \& Jones, D. I. H. (1973). In Chemistry and Biochemistry of Herbage. Vol. 2, p. 127. [G. W. Butler and R. W. Bailey, editors]. London: Academic Press.

Clarke, R. T. J. \& Reid, C. S. W. (1974). F. Dairy Sci. 57, 753.

Cooper, J. P. (1973). In Chemistry and Biochemistry of Herbage. Vol. 2, p. 379. [G. W. Butler and R. W. Bailey, editors]. London: Academic Press.

Davies, D. A. \& Morgan, T. E. H. (1979). Grass and Forage Sci. 34, 67.

Evans, W. B. Munro, J. M. M. \& Scurlock, R. V. (1979). Grass and Forage Sci. $34,64$.

Fleming, G. A. (1973). In Chemistry and Biochemistry of Herbage. Vol 1, p. 529. [G. W. Butler and R. W. Bailey, editors]. London: Academic Press.

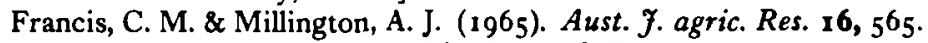

Gosden, A. F. (1978). Rep. Welsh Pl. Breed. Stn 1977 p. 226.

Jones, D. I. H. (1975). Rep. Welsh Pl. Breed. Stn 1974 P. 128.

Jones, D. I. H. \& Hayward, M. V. (1975). F. Sci. Fd Agric. 26, 7 r r.

Jones, D. I. H., Walters, R. J. K. \& Breese, E. L. (1974). Proc. 5th Gen. Mtg European Grassld Soc. p. 11 I.

Miles, D. G., Walters, R. J. K. \& Evans, E. M. (1969). Anim. Prod. I1, I9.

Moseley, G. \& Jones, J. R. (1979). Br. F. Nutr. 42, 139.

Patil, B. D. \& Jones, D. I. H. (1970). Proc. I Ith int. Grassld Congr. p. 726.

Raymond, W. F. (I 969). Adv. Agron. 2 1, 2.

Selim, O. I., Wilson, D. \& Jones, D. I. H. (I975). J. agric. Sci., Camb. 85, 297.

Ulyatt, M. J. (1973). In Chemistry and Biochemistry of Herbage. Vol. 3, p. I31. [G. W. Butler and R. W. Bailey, editors]. London: Academic Press.

Walters, R. J. K. (r 971). F. agric. Sci., Camb. 76, 243.

Walters, R. J. K. (1974). Proc. 5th Gen. Mtg European Grassld Soc. p. 184.

Wilson, D. (1965). F. agric. Sci., Camb. 65, 285. 